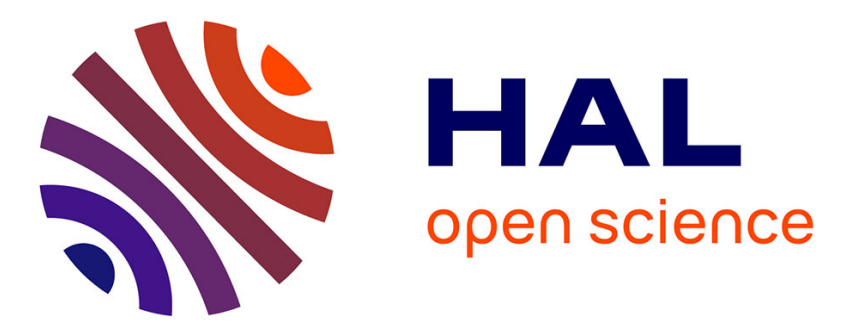

\title{
Exploring the nonlinear dynamics of bistable energy harvester
}

\author{
Vinicius Lopes, João Peterson, Americo Cunha Jr
}

\section{To cite this version:}

Vinicius Lopes, João Peterson, Americo Cunha Jr. Exploring the nonlinear dynamics of bistable energy harvester. XVIII International Symposium on Dynamic Problems of Mechanics (Diname 2019), Mar 2019, Armação dos Búzios, Brazil. hal-01974240

\section{HAL Id: hal-01974240 https://hal.science/hal-01974240}

Submitted on 8 Jan 2019

HAL is a multi-disciplinary open access archive for the deposit and dissemination of scientific research documents, whether they are published or not. The documents may come from teaching and research institutions in France or abroad, or from public or private research centers.
L'archive ouverte pluridisciplinaire HAL, est destinée au dépôt et à la diffusion de documents scientifiques de niveau recherche, publiés ou non, émanant des établissements d'enseignement et de recherche français ou étrangers, des laboratoires publics ou privés. 


\title{
Exploring the nonlinear dynamics of bistable energy harvester
}

\author{
Vinicius Gonçalves Lopes ${ }^{1}$, João Victor Ligier Lopes Peterson ${ }^{1}$, and Americo Cunha Jr ${ }^{1}$ \\ 1 Universidade do Estado do Rio de Janeiro - UERJ \\ NUMERICO - Nucleus of Modeling and Experimentation with Computers \\ Rua São Francisco Xavier, 524, Maracanã, Rio de Janeiro - RJ, Brasil \\ vinicius.lopes@uerj.br _joao.peterson@uerj.br _americo@ime.uerj.br
}

\section{Keywords: nonlinear dynamics, energy harvesting, basins of attraction, bifurcation diagrams}

Recent technology advances and increasing power demands have been encouraging renewable energies research, among which are the energy harvesting technologies (Pfenniger et al., 2014), (Spies, Pollak and Mateu, 2015). Energy harvesting devices are able to support low power applications such as boarded electrical circuits and sensors, medical electrical implants (e.g. pace-markers) and general low-power-consumption electrical equipment far from power supply, for example. Its concept consists of an electromechanical device able to capture environmental energy, available from natural or artificial sources as heat, pressure differences, vibration, etc, and converting it into an electrical potential. As nonlinearities may improve energy harvesting processes gains (Cottone, Vocca and Gammaitoni, 2009), this subject has been the object of study of recent works by Leite et al (2016), Peterson, Lopes and Cunha (2017), Lopes, Peterson and Cunha (2017) and Lopes, Peterson and Cunha (2018).

Motivated by necessity of investigate in deep the nonlinear phenomena underlying new energy harvesting systems, this work aims to characterize in detail, by means of bifurcation diagrams and attraction basins, a nonlinear bistable dynamical system associated to the electromechanical oscillator presented in Erturk, Hoffmann and Inman (2009). This characterization is necessary not only to have a better understanding of the basic physics underlying the energy harvesting system, but also to allow the optimization of its performance.

The energy harvesting system addressed in this work is the piezo-magneto-elastic beam schematically represented in Figure 1, proposed by Erturk, Hoffmann and Inman (2009). It consists on a cantilever slim ferromagnetic beam, attached to a rigid base driven by a harmonic forcing, which vibrates in a nonlinear regime due to the presence of a pair of magnets at the bottom of the base. On the top of this beam there is a piezoelectric transducer, which produces electrical potential when activated by mechanical pressure, that couples this mechanical structure to a resistive electrical circuit.

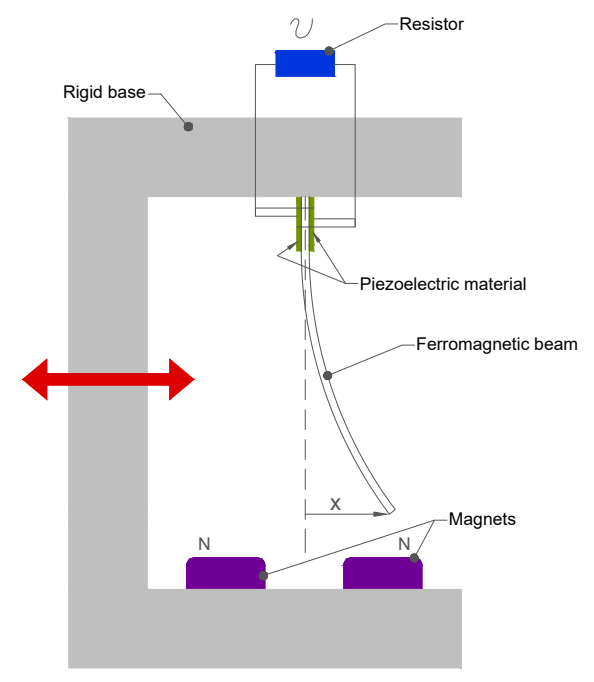

Figure 1 - Schematic representation of the piezo-magneto-elastic energy harvesting system. 
The behavior of this dynamical system model evolves according to

$$
\begin{gathered}
\ddot{x}+2 \xi \dot{x}-0.5 x\left(1-x^{2}\right)-\chi v=f \cos (\Omega t), \\
\dot{v}+\lambda v+\kappa \dot{x}=0,
\end{gathered}
$$

where $f$ and $\Omega$ represent harmonic forcing amplitude and frequency, respectively, $\xi$ and $\kappa$ are the mechanical and electrical piezo-electric coupling terms, $k s i$ is the damping ration and lambda is the time reciprocal constant. T beam tip displacement and velocity are given respectively by $x$ and $\dot{x}$, while output voltage is denoted as $v$.

Bifurcation diagrams are presented on Figure 2. Slices represents diagrams for system dynamics with excitation amplitudes uniformly incremented of 0.019 , from 0.019 to 0.275 . Frequencies on each slice are regularly sampled between 0.1 and 1.4 , both on forward and backward modes. Forward one considers $\Omega$ incremental sampling and is depicted by blue colors scale, while backward, a decremental, been shown on red colors scale. Chaotic dynamics are depicted by smudgy diagrams regions, more evident on higher amplitudes specially for frequencies from 0.1 to 0.6 , but also present on mean amplitudes about the second half of frequency control interval. Multi-periods regions also may be identified close to chaotic areas both after and before blurred regions or even between those non-regularities, what is featured in detail with the slice for an excitation amplitude of 0.147 , shown on the right. A noisy region, filled with discontinuities both on forward and backward diagrams is also noted for lower frequency values, comprised between 0.1 and 0.4.
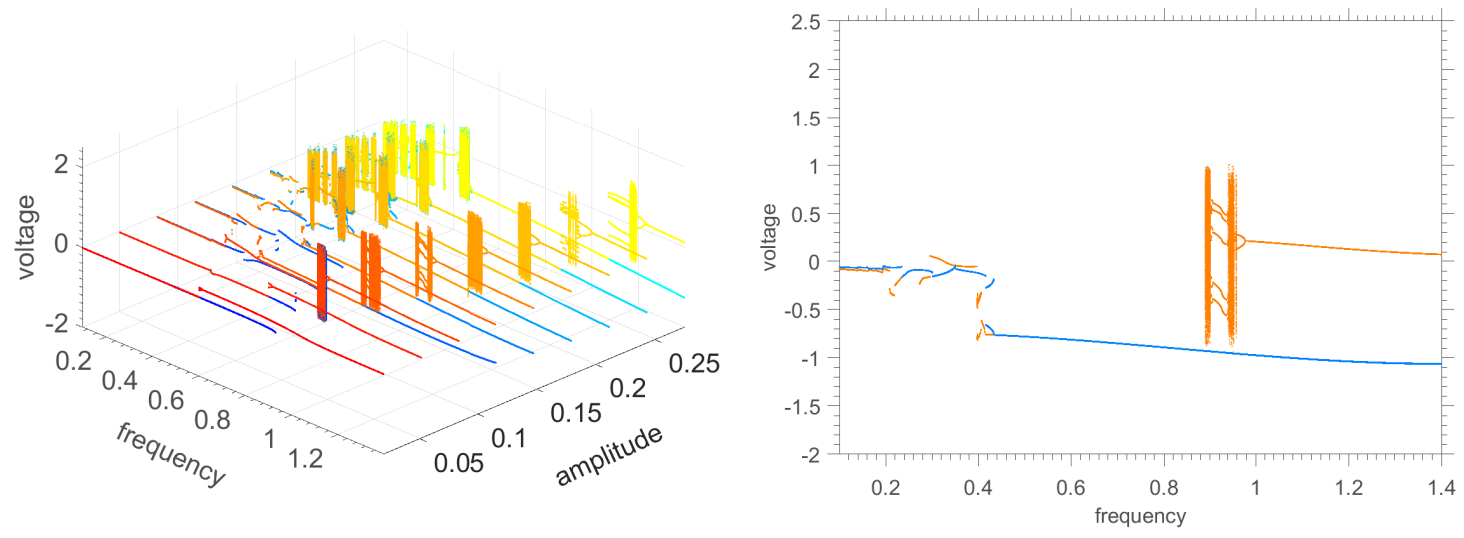

Figure 2 - Forward (blue scale) and backward (red scale) voltage bifurcation diagrams, in the left, with $0.1 \leq \Omega \leq 1.4$ and $f$ from 0.019 to 0.275 . The diagram that corresponds to $f=0.147$ is shown in the right.

A closer investigation of this discontinuities region by means of voltage time series, with excitation frequencies $\Omega=$ 0.2941 and $\Omega=0.3711$, reveals a regular dynamical behavior such as shown in Figure 3. Non-chaotic oscillation period is clearly identified both on forward and on backward time series, unlike what may be seen for $\Omega=0.9002$, presented on the same figure. In this conditions, backward analysis shows a non-periodic oscillation.
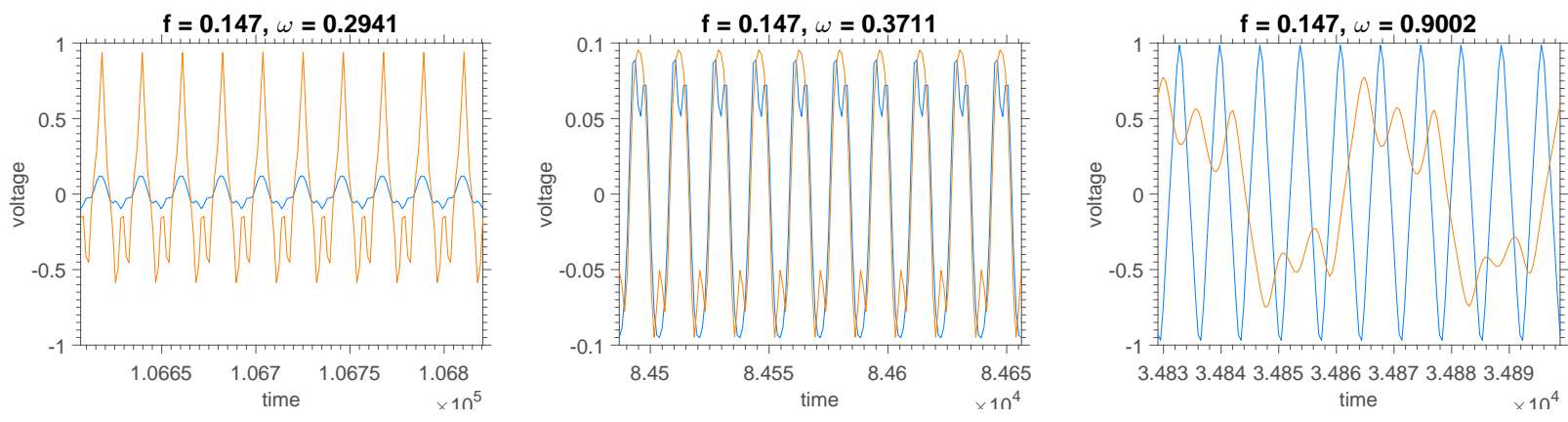

Figure 3 - Different time series of voltage associated to the forward (blue) and backward (orange) bifurcation diagrams with $f=0.147 ; \Omega=0.2941$ (left), $\Omega=0.3711$ (center) and $\Omega=0.9002$ (right).

In Figure 4, the basin of attraction corresponding to $\Omega=0.8$ and $f=0.051$ and their respective attractors are shown. It is possible to see the presence of six attractors, depicted in green, blue, cyan, red, magenta and a chaotic one in grey. The sensitivity to initial conditions is clear, although there are some zones where the behavior is well delimited, as in the green, red and blue zones. Is important to note that the green attractor is the most energetic, as it has the wider range both in displacement and velocity. 

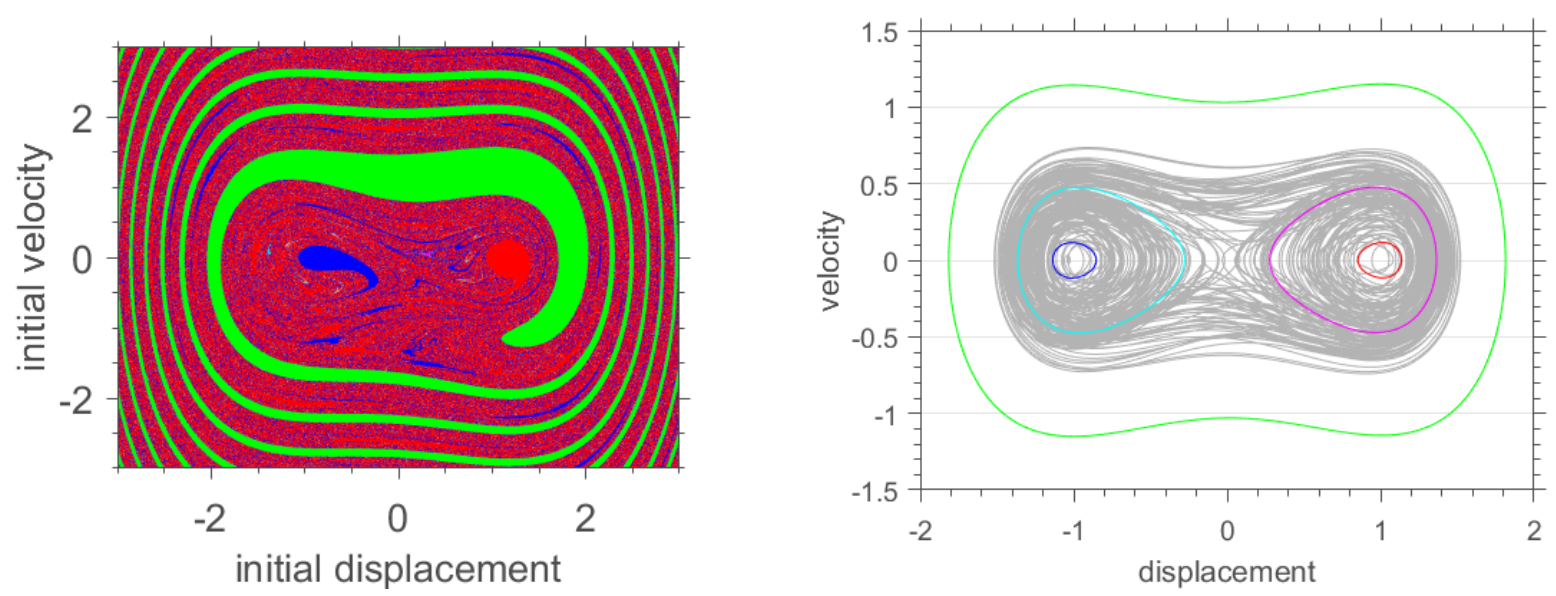

Figure 4 - Basin of attraction corresponding to $\Omega=0.8$ and $f=0.051$ (left) and their respective attractors (right).

\section{ACKNOWLEDGMENTS}

The third author acknowledge the support given to this research by the funding agencies Carlos Chagas Filho Research Foundation of Rio de Janeiro State (FAPERJ) under grants E-26/010.002.178/2015 and E-26/010.000.805/2018, and Coordenação de Aperfeiçoamento de Pessoal de Nível Superior - Brasil (CAPES) - Finance Code 001.

\section{REFERENCES}

F. Cottone, H. Vocca and L. Gammaitoni, Nonlinear Energy Harvesting Physical Review Letters, 102: $080601,2009$. https://doi.org/10.1103/PhysRevLett.102.080601

A. Erturk, J. Hoffmann, and D. J. Inman, A piezomagnetoelastic structure for broadband vibration energy harvesting, Applied Physics Letters, 94:254102, 2009. http://dx.doi.org/10.1063/1.3159815

T. Leite, A. S. de Paula, A. T. Fabro and M. Savi, A numerical analysis of the electrical output response of a nonlinear piezoelectric oscillator subjected to a harmonic and random excitation, In: XXXVII Iberian Latin American Congress on Computational Methods in Engineering, 2016.

J. V. L. L. Peterson, V. G. Lopes, and A. Cunha Jr, Dynamic analysis and characterization of a nonlinear bi-stable piezo-magneto-elastic energy harvester, MATEC Web of Conferences, 2018.

V. G. Lopes, J. V. L. L. Peterson, and A. Cunha Jr, Numerical study of parameters influence over the dynamics of a piezo-magneto-elastic energy harvesting device, In: XXXVII Congresso Nacional de Matemtica Aplicada e Computacional, 2017.

J. V. L. L. Peterson, V. G. Lopes, and A. Cunha Jr, On the nonlinear dynamics of a bi-stable piezoelectric energy harvesting device, In: 24th ABCM International Congress of Mechanical Engineering, 2017.

A. Pfenniger and A. Stahel and V. M. Koch and D. Obrist and R. Vogel, Energy harvesting through arterial wall deformation: A FEM approach to fluid-structure interactions and magneto-hydrodynamics, Applied Mathematical Modelling, 38: 3325-3338, 2014.

P. Spies and M. Pollak and L. Mateu, Handbook of Energy Harvesting Power Supplies and Applications, Pan Stanford, 2015.

\section{RESPONSIBILITY NOTICE}

The authors are the only responsible for the printed material included in this paper. 